\title{
RASPA DE MANDIOCA INTEGRAL DESIDRATADA NA ALIMENTAÇÃO DE CODORNAS JAPONESAS SOBRE A PRODUÇÃO DE OVOS E QUALIDADE DOS OVOS DURANTE A CONSERVAAÇÃO IN NATURA
}

\author{
Luiz Juliano Valério Geron ${ }^{1}$, Karine Barbosa Moraes ${ }^{1}$, Fabiana Gomes Costa ${ }^{1}$, \\ Raquel Joana Trautmann-Machado', Crislaine Messias de Souza Santos ${ }^{1}$, Pablo \\ Rodriguez Muniz ${ }^{1}$
}

\author{
1 UNEMAT \\ Correspondência: Luiz Juliano Valério Geron: ljgeron@yahoo.com.br
}

\begin{abstract}
RESUMO: Objetivou-se avaliar a produção e a qualidade de ovos de codornas japonesas em postura alimentadas com diferentes níveis de inclusão da raspa de mandioca integral desidratada (RMID). Foram utilizadas 100 codornas japonesas no pico de postura, distribuídas em quatro níveis de inclusão da RMID $(0,0 \% ; 10,0 \%, 20,0 \%$ e $30,0 \%)$. O delineamento experimental utilizado para o ensaio de produção foi inteiramente casualizado, os dados das variáveis estudadas foram interpretados por análise de variância e as diferenças observadas para as variáveis estudas foram submetidas a análise de regressão a $5 \%$ de significância. Para a avaliação do tempo de conservação in natura dos ovos foi considerado um fatorial $4 \times 3$, ou seja, quatro rações experimentais e 3 períodos ( $0 ; 12$ e 24 dias) de conservação dos ovos, os dados foram testados considerando teste Tukey a $5 \%$ de significância. Para a produção de ovos por dia das codornas foi observado que os diferentes níveis de inclusão da RMID não alteram $(P>0,05)$ o número de ovos para os diferentes tratamentos, com valor médio de 4,22 ovos gaiola ${ }^{-1} \mathrm{dia}^{-1}$. Para a qualidade dos ovos observou diferença significativa $(P<0,05)$ para as variáveis, peso da casca e espessura da casca em relação aos diferentes níveis de inclusão da RMID. Os dias de conservação in natura dos ovos influenciou $(\mathrm{P}<0,05)$ o diâmetro da gema (DIG), o diâmetro da câmera de ar (CAA) e o pH da gema (pHG), os quais apresentaram menor valor para o dia 0 em relação ao tempo de conservação de 12 e 24 dias. Assim, conclui-se que a inclusão de até $30,0 \%$ de raspa de mandioca integral desidratada não altera a produção de ovos de codornas por dia, além disso, o consumo dos ovos deve ser realizado antes de 12 dias de conservação in natura, garantindo um produto de qualidade ao consumidor.
\end{abstract}

Palavras-chave: alimento alternativo; aves; pico de postura; $\mathrm{pH}$ da gema

\section{SCRAPE INTEGRAL DEHYDRATED CASSAVA IN FEED OF QUAILS JAPANESE ON THE PRODUCTION OF EGGS AND EGG QUALITY DURING STORAGE IN NATURA}

\begin{abstract}
This study aimed to evaluate the production and egg quality of laying quails fed different levels of inclusion of scrape integral dehydrated cassava (SIDC). Ware used 100 Japanese quails in peak production, divided into four levels of inclusion of SIDC $(0.0 \%, 10.0 \%, 20.0 \%$ and $30.0 \%)$. The experimental design used for the production essay was completely randomized, the data of the studied variables were interpreted by analysis of variance and the differences observed for the variables studied were subjected to regression analysis at $5 \%$ significance. For the evaluation of the period conservation in natura of eggs was considered a $4 \times 3$ factorial experimental design, with four experimental diets and 3 periods ( 0,12 and 24 days) of preservation of eggs, the data were tested considering the Tukey test at $5 \%$ significance. For the production of quail eggs per day observed that different inclusion levels of SIDC does not affect $(P>0.05)$ the number of eggs in the different treatments, averaging 4.22 eggs cage ${ }^{-1}$ day $^{-1}$. For quality egg observed significant difference $(P<0.05)$ for the variables, shell weight and shell thickness in relation to different levels of inclusion of SIDC. The days of conservation in natura eggs influenced $(P<0.05)$ the diameter of the gemstone (DGE), the diameter of the camera air (CAA) and $\mathrm{pH}$ of yolk (PHG), which had value less for the day 0 in relation to period of conservation in natura of 12 and 24 days. It is therefore concluded that the inclusion of up to $30.0 \%$ of scrape integral dehydrated cassava does not alter the production of quail eggs per day, moreover, the intake of eggs must be performed before 12 days of storage in natura ensuring a quality product to the consumer.
\end{abstract}

Key Words: food alternative; birds; peak posture; $\mathrm{pH}$ yolk 


\section{INTRODUÇÃO}

Nos últimos anos, a coturnicultura no Brasil vem crescendo de maneira considerável e se tornando uma atividade atrativa e rentável. Esse sucesso vem da possibilidade de rápido retorno do capital investido, aliado ao alto valor nutritivo do seu ovo e à qualidade de sua carne. A codorna doméstica (Coturnix coturnix japonica) apresenta ciclo reprodutivo curto, precocidade sexual, boa fertilidade e ótima taxa de postura (MÓRI et al., 2005; TEIXEIRA et al., 2012).

A nutrição adequada é um dos fatores mais importantes na manutenção da condição física da codorna para se obter um crescimento normal e otimizar a produção de ovos. Assim, nutrientes como energia, proteínas, aminoácidos, minerais e vitaminas são primordiais para que a ave possa expressar seu máximo potencial genético e produtivo, produzindo ovos de máxima qualidade interna e externa (COSTA et al., 2010).

Segundo Calderano (2008) é importante à determinação da eficiência de energia, pois o conteúdo energético da ração pode influenciar o consumo e o desempenho dos animais, porém ao se determinar a energia metabolizável deve levar em consideração vários fatores tais como a variação na composição química de um mesmo alimento e a influencia da idade das aves, pois, com o avanço da idade e maturidade do sistema digestivo, as aves tendem a apresentar melhor digestibilidade da energia.

A recomendação de energia metabólica (EM) segundo Barreto et al. (2007) e Moura et al. (2009) para codornas em postura na fase inicial de 56 aos 168 dias, é de $2.900 \mathrm{kcal}$ de EM $\mathrm{kg}^{-1}$, na qual apresentaram melhor conversão alimentar por massa e por dúzia de ovos.
As exigências de proteína bruta (PB) têm recebido muita atenção, por causa dos altos custos das fontes proteicas. Segundo Bennett e Cheng (2010), com uma melhor compreensão das exigências de aminoácidos das codornas isso poderá propiciar um menor valor de proteína na dieta e consequentemente reduzir os custos dos alimentos além do impacto de sua excreta ao ambiente. Segundo Mattos Filho et al. (1999), o nível de 20 a $24 \%$ de proteína bruta é adequado para atender a exigência de aminoácidos e consequentemente alcançar o máximo peso de ovos de codornas em rações contendo $2.700 \mathrm{kcal}$ de energia metabolizável $\mathrm{kg}^{-1}$ de ração.

Segundo revisão realizada por Geron (2007), a busca por alimentos alternativos vem crescendo a cada dia, com a intenção de reduzir o custo de produção e manter os níveis adequados de produção de animais monogástricos.

Entre os alimentos alternativos, encontram-se os produtos e/ou subprodutos da industrialização da mandioca, em razão de seu potencial energético (MAZZUCO e BERTOL, 2000). De acordo com Brum e Albino (1993), a produtividade da mandioca apresentou um melhor rendimento que a do milho, embora seu ciclo de produção seja maior e a quantidade de matéria seca $(34 \%)$ seja menor que a do milho grão (87\%).

A mandioca (Manihot esculenta, Crantz) é uma planta brasileira de cultura alimentar, tendo vantagens como elevada rusticidade, facilidade de cultivo, elevada produtividade de raízes, podendo ser explorada, em solos marginais. Caracterizada como alimento energético, por ser rica em carboidratos, principalmente, na forma de amido. A raspa da raiz de mandioca destaca-se como fonte de energia, porém apresenta quantidades mínimas de proteína, vitaminas e minerais, cujos valores devem ser considerados e ajustados 

produção de ovos e qualidade dos ovos durante a conservação in natura

nas formulações de rações (FERREIRA, 2010).

Segundo estudo realizado por Nascimento et al. (2005), a utilização de $10,29 \%$ de farinha da raspa de mandioca em substituição ao grão de milho moído na alimentação de frangos de corte na fase inicial apresentou melhor $(P<0,05)$ conversão alimentar, porem na fase final dos frangos de corte a substituição do grão de milho pela farinha da raspa de mandioca apresentou valores de conversão alimentar $(\mathrm{P}<0,05)$ desfavorável.

Segundo Ferreira et al. (2012), a raspa integral da raiz de mandioca pode ser utilizada em dietas balanceadas de frangos de corte, no período de 1 a 42 dias, até o nível de $6,77 \%$, sem comprometer as características da carcaça e o rendimento dos principais cortes.

De acordo com Sarcinelli et al. (2007), os ovos são importantes fontes proteicas, sendo considerado alimentos ricos em proteína e com baixo teor de gordura, tendo na porção lipídica maiores concentrações de ácidos graxos instaurados.

O ovo é um produto de origem animal, e apresenta-se perecível ao longo do tempo, podendo ocorrer perdas da qualidade interna momento após a postura, caso não sejam tomada medidas adequadas para sua conservação. Desta maneira, a perda de qualidade do ovo é um fenômeno inevitável que acontece de forma contínua ao longo do tempo e pode ser agravado por diversos fatores (BARBOSA et al., 2008).

O ovo de codorna apresenta sabor semelhante ao de galinha, com coloração de casca que varia de castanho, branco e esverdeado, onde normalmente, podem apresentar manchas de cor preta a castanho claro, além disso, o tamanho pequeno dificulta as operações para obtenção de produtos a base destes ovos (BRESSAN e ROSA, 2002).

De acordo com Costa et al. (2006), a razão pela qual a maioria dos produtores de codornas tem perdas de ovos é devido ao manejo e a qualidade da casca, sendo está também influenciada por fatores como a idade e nutrição das aves. Entretanto, algumas medidas são usadas na avaliação dessa perda como a espessura de casca, a percentagem de casca, 0 peso específico entre outras variáveis.

Segundo Dutra et al. (2009), o ovo de codorna é um alimento altamente nutritivo, porém perecível, que com o tempo perde suas características qualitativas de forma gradativa. As principais alterações físico-químicas que afetam a qualidade interna dos ovos, logo após a postura são a perda de dióxido de carbono $\left(\mathrm{CO}_{2}\right)$ e a água através da evaporação do albúmen para - fluído externo; modificações bioquímicas das proteínas e perda de água da gema.

Para que os nutrientes contidos no interior dos ovos não sejam transformados rapidamente em substâncias impróprias para a alimentação, faz-se necessário que os ovos sejam armazenados sob refrigeração, e ovos embalados inadequadamente ou expostos a correntes de vento e a agentes contaminantes, e estocados sob temperatura elevada e baixa umidade têm alterações bioquímicas do albúmen mais aceleradas e estão mais propensos à contaminação por agentes patogênicos, os quais depreciam sua qualidade interna (MOURA et al., 2008).

Segundo Sarcinelli et al. (2007), a qualidade dos ovos está correlacionado ao valor de $\mathrm{pH}$ da gema e do albúmen. $\mathrm{O}$ ovo fresco apresenta $\mathrm{pH}$ da gema de 6,0 e do albúmen de 6,6. Depois de algum tempo, este $\mathrm{pH}$ é alterado, aumentando consideravelmente. Este 
fato ocorre devido ao elevado teor de $\mathrm{CO}_{2}$, encontrado no interior do ovo momento após a postura, e ao passar do tempo a concentração do $\mathrm{CO}_{2}$ no interior do ovo vai reduzindo devido as perdas deste gás pelos poros do ovo e consequentemente o $\mathrm{pH}$ tende a subir.

De acordo com Cruz et al. (2006), a farinha de apara de mandioca pode substituir o grão de milho na alimentação de aves em postura, porém os ovos das aves alimentadas com farinha de apara de mandioca apresentaram uma menor coloração em relação as aves alimentadas grão de milho.

Segundo Costa et al. (2009), a inclusão de $0 \%$; 5\%, 10\%, 15\%, 20\% e $25 \%$ de raspa de mandioca nas rações de poedeiras comerciais afetou negativamente $(P<0,05)$, a produção de ovos e a conversão alimentar das aves de postura.

Assim, objetivou-se avaliar a inclusão dos diferentes níveis de 0,0\%; $10,0 \% ; 20,0 \%$ e $30,0 \%$ de raspa de mandioca integral desidratada (RMID) na alimentação de codornas japonesas na fase de postura sobre a produção de ovos e a qualidade dos ovos durante 0 tempo de 0,12 e 24 dias de conservação in natura.

\section{MATERIAL E MÉTODOS}

O experimento foi realizado no Campus Universitário de Pontes e Lacerda no Setor de Metabolismo Animal (SeMA) e no Laboratório de Análise de Alimentos e Nutrição Animal (LAANA) pertencente à Universidade do Estado de Mato Grosso - UNEMAT.

A raspa de mandioca integral foi obtida de pequenas propriedades, ou seja, da agricultura familiar existente no município de Pontes e Lacerda - MT.

Foi utilizado um delineamento experimental inteiramente casualizado (DIC) com 100 codornas distribuídas em vinte gaiolas contendo cinco animais cada, totalizando cinco repetições (gaiolas) tratamento $^{-1}$, com quatro rações experimentais contendo diferentes níveis $(0,0 ; 10,0 \% ; 20,0 \%$ e $30,0 \%$ ) de inclusão da raspa de mandioca integral desidratada (RMID) na alimentação de codornas para comparar a produção de ovos, altura e diâmetro dos ovos.

A RMID foi obtida após a picagem da raiz de mandioca in natura com a casca em um desintegrador de forragem e em seguida a massa de mandioca, ou seja, a raspa foi colocada para desidratar ao sol por três dias até a obtenção da raspa de mandioca integral desidratada (RMID), a qual apresentou teor de matéria seca (MS) de $89,71 \%$.

No ensaio de desempenho produtivo (produção de ovos) foram utilizados os seguintes ingredientes para a formulação das rações experimentais raspa de mandioca integral desidratada, milho grão moído, farelo de soja, óleo de soja, núcleo vitamínico e mineral e calcário. Foram confeccionadas quatro rações experimentais contendo diferentes níveis de inclusão de RMID $(0,0 \% ; 10,0 \% ; 20,0 \%$ e $30,0 \%$ na MS).

A composição bromatológica dos alimentos utilizados no experimento está demonstrada na Tabela 1, estes valores da composição bromatológica dos alimentos foram utilizados para estimar a composição percentual e bromatológica das rações experimentais (Tabela 2).

As rações experimentais foram balanceadas para apresentarem 20,0\% de proteína bruta- PB (isoprotéica) e $2.900 \mathrm{kcal}$ de energia metabolizável EM de acordo com o Teixeira (2001), as rações experimentais foram fornecidas três vezes ao dia às 7 horas, 12 horas e 18 horas em comedouro tipo calha. 
Raspa de mandioca integral desidratada na alimentação de codornas japonesas sobre a produção de ovos e qualidade dos ovos durante a conservação in natura

Tabela 1- Composição bromatológica dos alimentos experimentais.

\begin{tabular}{|c|c|c|c|c|c|c|c|}
\hline \multirow[b]{2}{*}{ Alimentos } & \multicolumn{7}{|c|}{ Nutrientes expressos em \% da MS } \\
\hline & $\overline{\mathrm{MS}} \%$ & MO & PB & $\mathrm{EE}$ & FDN & MM & 'EM Mcal \\
\hline Raspa de mandioca desid. & 89,71 & 97,49 & 2,95 & 1,46 & 16,55 & 5,03 & 2,80 \\
\hline Grão de milho moído & 89,37 & 98,36 & 9,83 & 4,18 & 14,05 & 1,66 & 3,38 \\
\hline Oleod & 98,00 & 98,00 & 0,00 & 0,00 & 0,00 & 0,00 & 8,79 \\
\hline Farelo de so & 89,29 & 92,69 & 47,55 & 1,75 & 15,37 & 6,38 & 2,29 \\
\hline Núcleo vit. e min. & 100 & 10,00 & 0,00 & 0,00 & 0,00 & 90,00 & 0,00 \\
\hline Calcário & 100 & 2,00 & 0,00 & 0,00 & 0,00 & 98,00 & 0,00 \\
\hline
\end{tabular}

Foram utilizadas 100 codornas japonesas na fase de postura com peso corporal $(P C)$ médio de $0,156 \mathrm{~kg}$ com aproximadamente 100 dias de vida. Os animais foram alojados em 20 gaiolas de metabolismo, cada gaiola de metabolismo continha cinco codornas, desta maneira as unidades experimentais foram às gaiolas e não 0 animal individual. As codornas tiveram livre acesso a água potável.

O ensaio de desempenho produtivo das codornas (ovos dia ${ }^{-1}$ ) foi conduzido durante 60 dias, onde os primeiros 12 dias foram de adaptação, ocorrendo a coleta e mensuração da quantidade de ovos por gaiola tratamento $^{-1}$ diariamente às 17 horas, sendo anotados os números de ovos produzidos, incluindo os imperfeitos (quebrados, trincados ou sem casca), porém na pesagem dos mesmos, descontava se os imperfeitos (CRUZ et al., 2006). Os ovos também foram mensurados quanto o seu comprimento e diâmetro diariamente.

Tabela 2 - Composição percentual e bromatológica das rações experimentais.

\begin{tabular}{|c|c|c|c|c|}
\hline \multirow[t]{2}{*}{ Alimentos } & \multicolumn{4}{|c|}{$\begin{array}{l}\text { Niveis de inclusão da raspa de mandioca } \\
\text { integral desidratada nas raçôes } \\
\text { experimentais }\end{array}$} \\
\hline & $0,0 \%$ & $10,0 \%$ & $20,0 \%$ & $30,0 \%$ \\
\hline \multicolumn{5}{|c|}{ Composição percentual das raçôes experimentais } \\
\hline Raspa de mandioca desidratada & 0,0 & 10,0 & 20,0 & 30,0 \\
\hline Grão de milho moído & 59,6 & 46,9 & 33,9 & 21,3 \\
\hline Oleo de soja & 2,8 & 3,5 & 4,3 & 5,1 \\
\hline Farelo de & 30,0 & 32,0 & 34,2 & 36,0 \\
\hline Núcleo vit e min & 6,0 & 6,0 & 6,0 & 6,0 \\
\hline Calcário & 1,6 & 1,6 & 1,6 & 1,6 \\
\hline Total & 100,0 & 100,0 & 100,0 & 100,0 \\
\hline \multicolumn{5}{|c|}{ Composição bromatológica (\% na MS) das rações experimentais } \\
\hline Variáveis & & & & \\
\hline Matéria seca(MS) & 90,40 & 90,49 & 90,59 & 90,69 \\
\hline orgânica (MO) & 89,8 & 89,6 & & 89,19 \\
\hline Proteína bruta (PB) & 20,12 & 20,12 & 20,18 & 20,10 \\
\hline Extrato etéreo (EE) & & 2,67 & 2,31 & 1,96 \\
\hline Fibra em detergente neutro (FDN) & 12,98 & 20,16 & 27,33 & 34,49 \\
\hline Matéria mineral (MM) & 9,87 & 10,29 & 10,72 & 11,13 \\
\hline Energia metabolizável EM Mcal kg-1 & 2,94 & 2,91 & 2,87 & 2,84 \\
\hline
\end{tabular}

No trigésimo dia do ensaio de desempenho produtivo foram coletados ovos, os quais foram identificados por gaiola tratamento ${ }^{-1}$ para a avaliação da qualidade (peso da casca, peso da gema e albúmen, altura e diâmetro da gema, diâmetro da câmera de ar, espessura da casca e pH da gema e do albúmen) no tempo de 0,12 e 24 dias de conservação in natura dos ovos.

Para avaliação da qualidade dos ovos foi realizado 0 seguinte procedimento, cada ovo foi quebrado com o auxílio de uma faca, em cima de uma superfície plana (placa de vidro) e em seguida procedeu-se a separação manualmente da gema e do albúmen. Para medição da altura e diâmetro da gema foi utilizada o paquímetro digital, com o mesmo equipamento mensurou a câmera de ar dos ovos e aferiu a espessura da casca, utilizando-se fragmentos de casca de três regiões polo superior, polo inferior e do meridiano da casca do ovo (COSTA et al., 2009). Com estas três medidas da casca do ovo realizou-se a média aritmética da espessura da casca de cada ovo.

A mensuração do $\mathrm{pH}$ da gema dos ovos foi realizada após a separação manual da gema do albúmen em cima de uma superfície lisa e em seguida colocou-se a gema dentro de um tubo de ensaio para mensurar o valor de $\mathrm{pH}$ por meio de um peagâmetro digital de bancada e posteriormente realizou-se 0 mesmo procedimento com o albúmen para mensuração do pH (SARCINELLI et al., 2007).

A pesagem dos diferentes constituintes dos ovos foi realizada separadamente para a casca, gema e albúmen, em balança analítica de precisão (CRUZ et al., 2006).

Para a avaliação da qualidade dos ovos após o tempo de conservação in natura de 0, 12 e 24 dias foi utilizado um esquema fatorial $4 \times 3$, para avaliar os quatro níveis $(0,0 ; 10,0 \% ; 20,0 \%$ e $30,0 \%)$ de RMID e três períodos de conservação (0, 12 e 24 dias). 
A análise das variáveis estudadas foi interpretada por meio de análise de variância no programa Sistema de Análise Estatística e Genética - SAEG (Universidade Federal de Viçosa, 1997). As diferenças observadas para os níveis de inclusão da RMID sobre a produção de ovos, altura e diâmetro dos ovos foram determinadas por análise de regressão considerando $5 \%$ de significância. Para a avaliação da qualidade dos ovos em função do tempo de conservação os dados foram submetidos a teste de média (Tukey) considerando $5 \%$ de significância.

\section{RESULTADOS E DISCUSSÃO}

A produção dos ovos de codornas não foi alterada $(P>0,05)$ com a inclusão dos diferentes níveis de RMID (0,0\%; $10,0 \% ; 20,0 \%$ e $30,0 \%$ ) nas rações (Tabela 3). Porém os valores obtidos para o peso, altura e diâmetro dos ovos de codornas foram alterados $(P<0,05)$ com a inclusão do RMID nas rações (Tabela 3).

Tabela 3 - Valores de produção, peso, altura e diâmetro dos ovos de codornas alimentadas com diferentes niveis de raspa de mandioca integral desidratada.

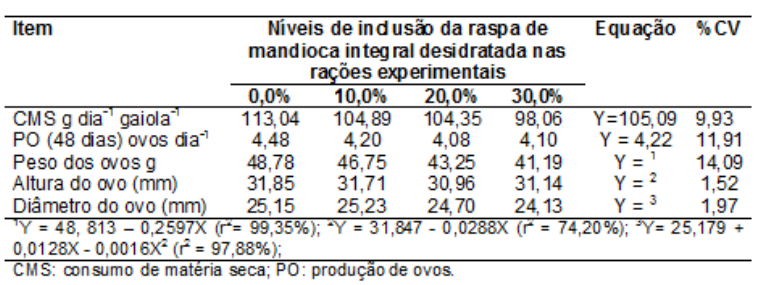

Este valor obtido para a produção de ovos $\mathrm{dia}^{-1}$ ocorreu provavelmente devido as rações experimentais terem apresentado os mesmos valores de proteína bruta de $20,1 \%$ e energia metabolizável de 2,9 Mcal de $\mathrm{EM} \mathrm{kg}^{-1}$ de MS (Tabela 2) atendendo a necessidade de produção das codornas que é em média um ovo dia ${ }^{-1}$. Além disso, as codornas apresentaram consumo de MS semelhante $(P>0,05)$ para os diferentes níveis de inclusão do RMID (Tabela 1).

$O$ efeito linear decrescente $(\mathrm{P}<0,05)$ observado para o peso e altura dos ovos de codornas alimentadas com diferentes níveis de RMID (Figura 1 A e $B$ ), pode ter ocorrido divido a um efeito associativo negativo sobre a digestão e absorção dos nutrientes decorrente ao maior teor de fibra em detergente neutro (FDN) das rações com os maiores níveis de RMID na dieta (Tabela 2). Além deste fato, o RMID apresentou uma característica de alta pulverulência o que pode ter contribuído para uma maior seleção de ingredientes no comedouro corroborando com o menor aporte de nutrientes para 0 desenvolvimento dos ovos.

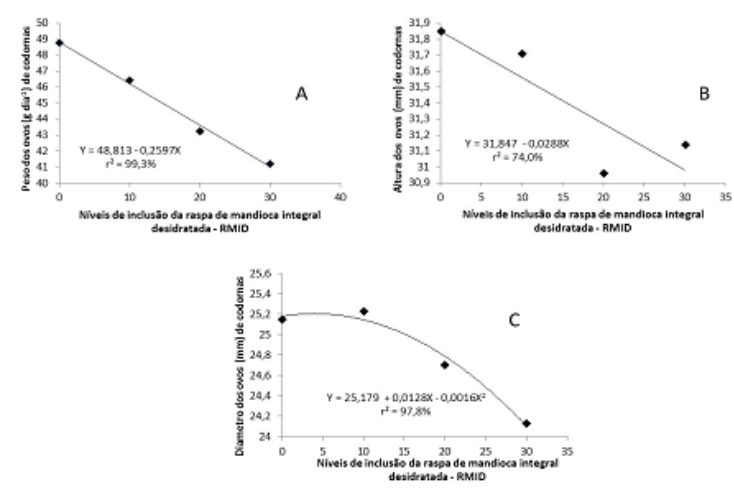

Figura 1 - Valores do peso dos ovos (A), da altura dos ovos (B) e do diâmetro dos ovos (C) de codornas alimentadas com raốes contendo diferentes níveis de inclusão da raspa de mandioca integral desidratada

Os diferentes níveis de RMID $(0,0 \% ; 10,0 \% ; 20,0 \%$ e $30,0 \%)$ na alimentação de codornas em postura influenciaram de maneira quadrática $(\mathrm{P}<0,05)$ o diâmetro dos ovos (Figura 1 C). O ponto de máximo para o diâmetro dos ovos de codornas foi de $25,21 \mathrm{~mm}$ estimado para o nível de $4,0 \%$ de RMID nas rações.

Estudo realizado por Costa et al. (2009) demonstrou que os níveis de raspa de mandioca $(0,0 \% ; 5,0 \% ; 10,0 \%$; $15,0 \% ; 20,0 \%$ e $25,0 \%$ ) na alimentação de poedeiras semipesadas, não influenciaram $(P>0,05)$ o peso médio do ovo, entretanto observaram efeito linear decrescente $(P<0,05)$ sobre a produção de ovos, que diminuiu à medida que se aumentou o nível de inclusão de raspa de mandioca na ração.

$\mathrm{Na}$ avaliação da substituição do milho pela farinha da apara de mandioca em rações experimentais em 
Raspa de mandioca integral desidratada na alimentação de codornas japonesas sobre a produção de ovos e qualidade dos ovos durante a conservação in natura

níveis crescentes $(0,0 \% ; 25,0 \% ; 50,0 \%$; $75,0 \%$ e $100,0 \%$ ) para poedeiras, realizado por Cruz et al. (2006) foi observado que a produção de ovos não foi influenciada $(P>0,05)$ pelos níveis crescentes da farinha de apara de mandioca. Entretanto os autores observaram que 0 peso do ovo apresentou efeito quadrático $(P<0,05)$ crescente com a inclusão da farinha de apara de mandioca na ração e observaram que o melhor resultado para o peso do ovo de $65,41 \mathrm{~g}$ foi obtido para as aves alimentadas com $50,0 \%$ de substituição do milho pela farinha da apara de mandioca.

Para a avaliação da qualidade dos ovos em relação ao tempo de conservação in natura de 0,12 e 24 dias, não foi observada alteração $(P>0,05)$ para o peso da casca (PEC) e gema (PEG) conforme demonstrado na Tabela 4. A inclusão do RMID na alimentação das codornas em postura não influenciou $(P>0,05)$ a altura da gema (ALG), diâmetro da gema (DIG), peso da gema (PEG) e peso do albúmen (PEA) como demonstrado na Tabela 4.

O tempo de conservação de $0 ; 12$ e 24 dias não alterou $(P>0,05)$ o peso da casca dos ovos das codornas, porém o peso da casca dos ovos (PEC) apresentou efeito quadrático $(P<0,05)$ com a inclusão dos diferentes níveis de RMID na dieta (Tabela 4) para todos os tempos $(0,12$ e 24 dias $)$ de conservação in natura. $O$ ponto de máximo observado para o peso da casca dos ovos foi obtido para o nível de $4,0 \%$ de RMID com o peso estimado de $1,25 \mathrm{~g}$ conforme a Figura 2.

Porém, o tempo de 0; 12 e 24 dias de conservação in natura dos ovos alteraram $(P<0,05)$ a altura da gema (ALG) dos ovos, sendo que o valor médio de $12,82 \mathrm{~mm}_{\text {ovo }}{ }^{-1}$, para o dia 0 de conservação foi superior aos valores médios de 8,16 e 7,01 mm ovo-1, respectivamente para os dias de 12 e 24 de conservação in natura.

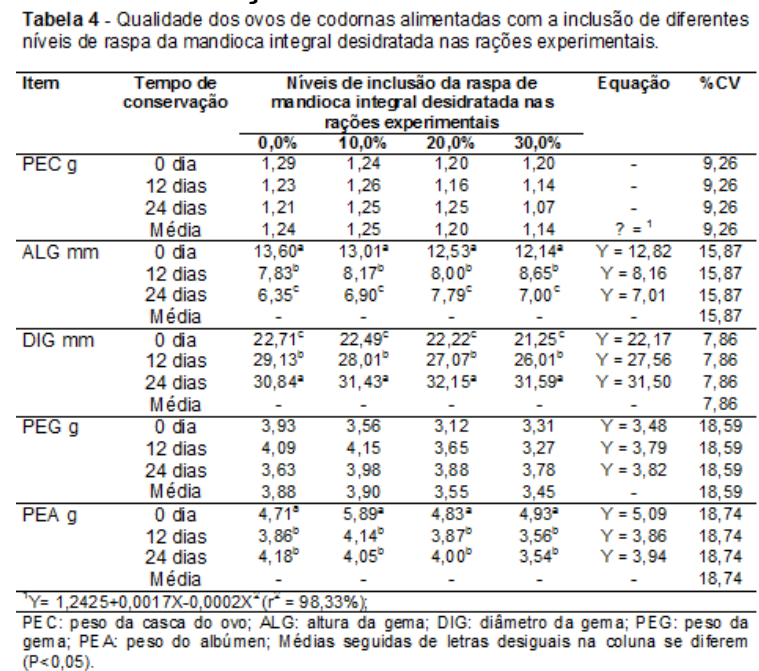

O acréscimo nos dias de conservação in natura promoveu um aumentou $(P<0,05)$ no diâmetro da gema (DIG) dos ovos, onde o valor médio observado para o dia 0 de conservação foi de 22, $17 \mathrm{~mm}$ inferior aos valores médios de 27,56 e 31,50 $\mathrm{mm}$, respectivamente para os dias $12 \mathrm{e}$ 24 de conservação in natura dos ovos (Tabela 4). Este efeito provavelmente foi devido a menor qualidade do ovo, o qual com o passar do período de conservação in natura provavelmente perdeu eletrólitos e água contribuindo nas alterações da conformação da forma estrutural e na altura da gema dos ovos de codornas.

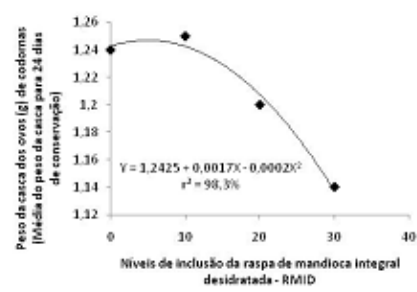

Figura 2 - Peso da casca dos ovos de codornas alimentadas com diferentes niveis de inclusão da raspa de mandioca integral desidratada.

O período de conservação in natura de 12 e 24 dias dos ovos apresentaram menor $(\mathrm{P}<0,05)$ valor médio para o peso do albúmen (PEA) de 3,86 e $3,94 \mathrm{~g}$ respectivamente, em relação ao dia 0 de conservação com valor médio de $5,09 \mathrm{~g}$ (Tabela 4). Este fato corrobora com a provável perda de 
água que ocorreu do interior do ovo para o exterior com o passar do período de conservação in natura. Segundo Dutra et al. (2009), a perda de água que ocorre por evaporação da albúmen e da gema dos ovos são uma das principais causas das alterações físico-químicas que alteram a qualidade dos constituintes dos ovos.

O tempo de conservação in natura de $0 ; 12$ e 24 dias não alterou $(P>0,05)$ a espessura da casca (ESC) dos ovos de codornas alimentadas com os diferentes níveis de RMID (Tabela 5). Porém para os valores de câmara de ar (CAA), pH da gema (pHG) e da albúmen (pHA) dos ovos de codornas apresentaram diferenças $(P<0,05)$ para os diferentes tempos de conservação in natura.

A inclusão do RMID na alimentação das codornas não influenciou $\quad(P>0,05) \quad 0 \quad$ tamanho (diâmetro) da câmara de ar (CAA) como demonstrado na Tabela 5. Porém, o tempo de conservação in natura de 0 ; 12 e 24 dias alterou $(P<0,05)$ a CAA dos ovos de codornas alimentadas com os diferentes níveis de RMID, onde a CAA apresentou maior valores para o tempo de conservação de 24 dias in natura (Tabela 5).

A espessura da casca (ESC) dos ovos de codorna apresentou efeito linear $(P<0,05)$ decrescente com a inclusão dos diferentes níveis de RMID na dieta (Tabela 5) para todos os tempos de conservação in natura. $O$ valor estimado segundo a equação $Y=$ 0,230 - 0,001X, para a determinação da ESC do ovo de codorna foi de $0,20 \mathrm{~mm}$, obtido para o nível de $30,0 \%$ de RMID (Figura 3).

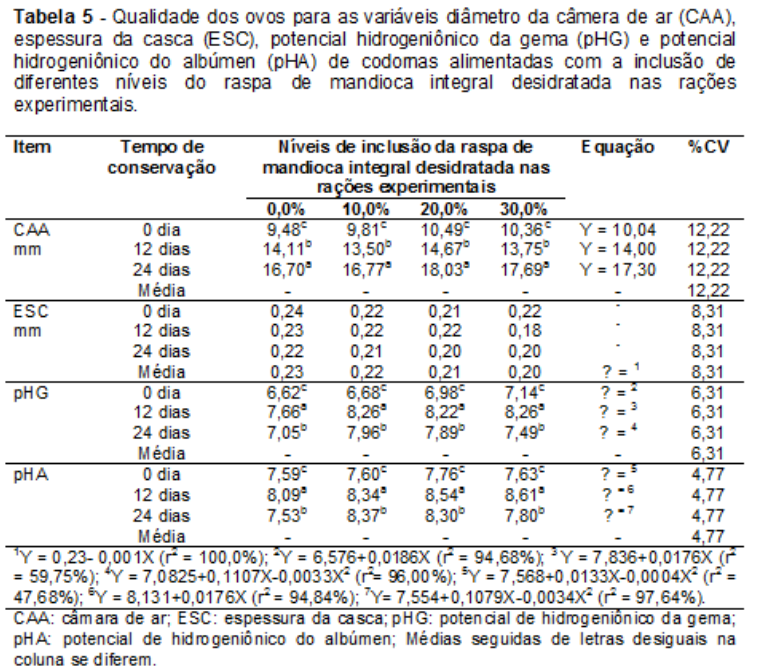

Segundo Cruz et al. (2006), a espessura de casca (ESC) do ovo de galinhas poedeiras apresentou efeito quadrático $(P<0,05)$ com a inclusão da farinha da apara de mandioca, os mesmos autores ainda observaram que o maior valor para a ESC foi obtida para as aves alimentadas com rações contendo $100 \%$ de milho. Estes autores sugeriram que provavelmente, a baixa concentração de cálcio na farinha da apara de mandioca em comparação ao grão de milho, pode ter contribuído para este efeito observado.

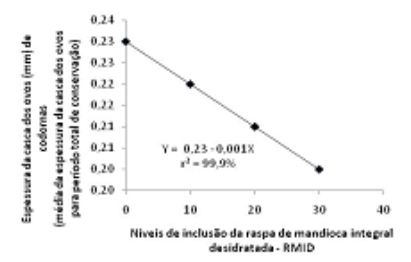

Figura 3 - Espessura da casca dos ovos de codornas alimentadas com diferentes níveis de inclusão do raspa de mandioca integral desidratada.

Os maiores valores de $\mathrm{pH}$ da gema (pHG) e do albúmen (pHA) dos ovos de codornas foram observados para o tempo de 12 dias de conservação in natura (Tabela 5). Entretanto os valores do pHG e pHA dos ovos de codornas conservados in natura durante $0 ; 12$ e 24 dias apresentaram comportamento variado $(P<0,05)$ linear ou quadrático em função dos diferentes níveis de inclusão da RMID (Tabela 5).

Para o pHG dos ovos de codornas foi observado efeito linear crescente $(P<0,05)$ em função da inclusão dos 

produção de ovos e qualidade dos ovos durante a conservação in natura

diferentes níveis de RMID para o tempo de conservação de 0 e 12 dias (Figura 4). Porém foi observado efeito quadrático $(\mathrm{P}<0,05)$ para $\mathrm{o}$ valor do pHG em função da RMID para o período de conservação de 24 dias. $O$ ponto de máximo estimado para o valor do $\mathrm{pHG}$ dos ovos foi de 8,01 obtido para o nível de $17,0 \%$ de RMID na ração (Figura 4) para o tempo de conservação in natura de 24 dias.

Provavelmente, esta variação no comportamento do valor do $\mathrm{pHG}$ pode ser devido as diferenças $(P<0,05)$ observadas entre os dias de conservação in natura (Tabela 5), o qual pode ter alterado a composição físicoquímica da gema do ovo e consequentemente ter influenciado na mudança da composição química e do comportamento do pHG com a inclusão RMID ao longo do período de conservação total de 24 dias.

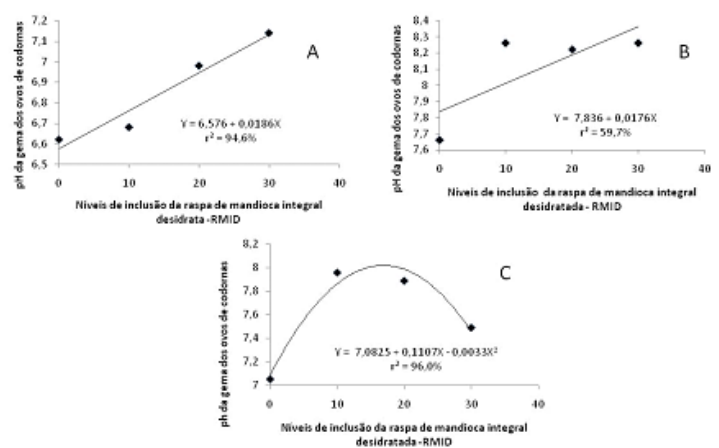

Figura 4 - Valor de potencial de hidrogênio da gema (pHG) dos ovos para dia zero de conservação (A), para 12 dias de conservação (B) e para 24 dias de raspa de mandioca integral desidratada - RMID.

O valor do pHA dos ovos de codornas apresentou efeito quadrático $(\mathrm{P}<0,05)$ com a inclusão da RMID para o período de conservação in natura dos ovos de 0 e 24 dias (Figura 5). Entretanto, foi observado efeito linear crescentes $(\mathrm{P}<0,05)$ para o $\mathrm{pHA}$ dos ovos em função dos diferentes níveis de inclusão da RMID durante o período de conservação de 12 dias (Figura 5).

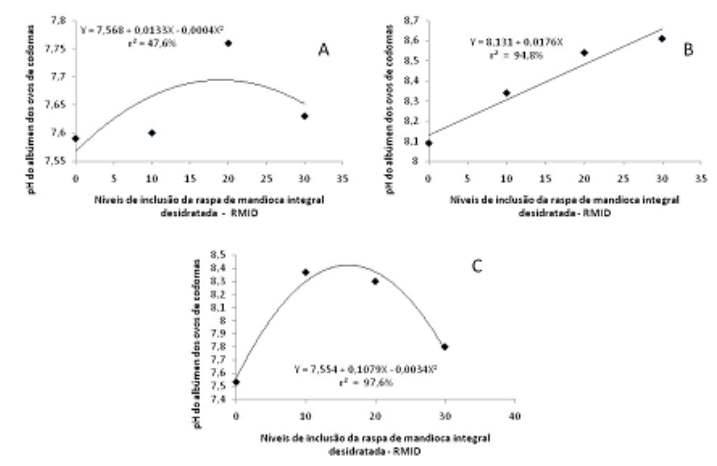

Figura 5 - Valor de pH do albúmen dos ovos para o período de conservados in natura das codornas alimentadas com diferentes niveis de inclusão do raspa de mandioca integral desidratada.

Os menores $(\mathrm{P}<0,05)$ valores de pHA dos ovos de codornas foram observados para o tempo de 0 dias de conservação in natura em relação aos demais dias (12 e 24 dias). Esta variação no valor do pHA dos ovos durante o tempo de conservação pode auxiliar na compreensão da variação observada no comportamento desta variável em relação a RMID. De acordo com Sarcinelli et al. (2007), o pH da albúmen ou da gema pode ser alterado devido ao teor de $\mathrm{CO}_{2}$, encontrado no interior do ovo, pois quando o ovo está no interior da galinha, ao respirar, ela produz o gás que é dissolvido em excesso na água do ovo. Desta maneira, quando o ovo está no exterior do aparelho reprodutivo, ocorre perda de água e $\mathrm{CO}_{2}$ através dos poros, portanto poderá existir menor concentração de $\mathrm{CO}_{2}$ dentro do ovo, o que significa menos $\mathrm{H}_{3} \mathrm{O}^{+}$a ser produzido e consequentemente o $\mathrm{pH}$ da gema ou da albúmen do ovo tende a se elevar durante 0 período de conservação.

\section{CONCLUSÃO}

Conclui-se que a inclusão de até $30,0 \%$ de raspa de mandioca integral desidratada não altera a produção de ovos de codornas $\mathrm{dia}^{-1}$. Os valores de $\mathrm{pH}$ da gema e albúmen dos ovos de codornas alimentadas com os diferentes níveis de raspa de mandioca integral desidratada apresentam diferentes 
comportamentos dentro do período e conservação in natura de até 24 dias, sendo que o consumo dos ovos deve ser realizado antes de 12 dias de conservação in natura, garantindo um produto de qualidade ao consumidor.

\section{REFERÊNCIAS}

BARBOSA, N. A. A.; SAKOMURA, N. K.; MENDONÇA, M. O. et al. Qualidade de ovos comerciais provenientes de poedeiras comerciais armazenados sob diferentes tempos e condições de ambientes. ARS Veterinária, v.24, n.2, p.127-133, 2008.

BARRETO, S. L. T.; QUIRINO, B. J. S.; BRITO, C. O. et al. Efeitos de Níveis Nutricionais de Energia Sobre o Desempenho e a Qualidade de Ovos de Codornas Européias na Fase Inicial de Postura. Revista Brasileira de Zootecnia, v.36, n.1, p.86-93, 2007.

BENNETT, D. C.; CHENG, K. M. Exigências nutricionais da codorna japonesa. In: SIMPÓSIO INTERNACIONAL, 4; CONGRESSO

BRASILEIRO DE COTURNICULTURA, 3, 2010, Lavras. Anais... Lavras: UFLA/NECTA, 2010. p.89-104.

BRESSAN, M. C.; ROSA, F. C. Processamento e industrialização de ovos de codorna. In: SIMPOSIO INTERNACIONAL DE COTURNICULTURA- NOVOS CONCEITOS APLICADOS Á CRIAÇÃO DE CODORNAS, 1 , 2002, Lavras. Anais... Lavras: UFLA/NECTA, 2002. CD-ROM.

BRUM, P. A. R. de; ALBINO, L. F. T. Farinha integral e raspa residual de mandioca na alimentação de frangos de corte. Comunicado Técnico EMBRAPA. Março/1993.

CALDERANO, A. A. Determinação de valores de energia metabolizável de alimentos para aves. Revista Eletrônica Nutritime, v.5, n.5, p.626-637, set./out. 2008.

COSTA, C. H. R.; ANGELINI, M. S.; SOUSA, M. F. et al. Efeito da idade de codornas japonesa (Coturnix Coturnix Japonica) sobre a postura e características físicas dos ovos produzidos. In: CONGRESSO DE ZOOTECNIA, ZOOTEC, 2006, Pernambuco. Anais... Universidade Federal Rural de Pernanbuco, 2006, Cd-Row.

COSTA, F.G.P.; SILVA, J.H.V. da; LIMA, M.R. et al. Relação entre exigências nutricionais vs qualidade de ovos de codornas japonesas. In: SIMPÓSIO INTERNACIONAL, 4; CONGRESSO BRASILEIRO DE COTURNICULTURA, 3, 2010,
Lavras. Anais... Lavras: UFLA/NECTA, 2010. p. 50-70.

COSTA, F. G. P.; GOULART, C. C.; COSTA, J. $S$. et al. Desempenho, qualidade de ovos e analise econômica da produção de poedeiras semipesadas alimentadas com diferentes níveis de raspa de mandioca. Acta Scientiarum. Animal Sciences, v.31, n.1, p.13-18, 2009.

CRUZ, F. G. G.; PEREIRA FILHO, M.; CHAVES, F. A. L. Efeito da Substituição do Milho pela Farinha de Mandioca em Rações para Poedeiras Comerciais. Revista Brasileira de Zootecnia, v.35, n.6, p.2303-2308, 2006.

DUTRA, D. R.; PEREIRA, D. C. O.; SANTOS, M. et al. Efeito da utilização de farinha de casca de ovo de codorna sobre a qualidade interna dos ovos de codornas japonesas em diferentes períodos de estocagem. In: CONGRESSO DE ZOOTECNIA, ZOOTEC, 14, 2009, Águas de Lindóia-SP. Anais... Universidade Estadual de São Paulo - UNESP, 2009.

FERREIRA, A. H. C. Raspa integral da raiz de mandioca para frangos de corte. 2010. 89 p. Dissertação (Mestrado em Ciência Animal), Universidade Federal do Piauí, Programa de Pós-Graduação em Ciência Animal, Teresina, 2010.

FERREIRA, A. H. C.; LOPES, J. B.; ABREU, M. L. T. et al. Raspa integral da raiz de mandioca para frangas de um a 42 dias de idade. Revista Brasileira de Saúde e Produção Animal, v.13, n.1, p.160-172, jan/mar. 2012.

GERON, L.J.V. Utilização de resíduos agroindustriais na alimentação de animais de produção. PUBVET, v1, n.9, p.312, 2007.

MATTOS FILHO, A. C. S; PEDROSO, A. A.; MORAES, V. M. B.; et al. Níveis de proteína em rações de codornas durante a fase de postura. ARS Veterinária, v.15, n.3, p.223-225, 1999.

MAZZUCO, H.; BERTOL, T. M. Mandioca e seus subprodutos na alimentação de aves e suínos. Circular técnica, Concórdia- SC: Embrapa Suínos e Aves, 2000. 37p.

MÓRI, C.; GARCIA, E. A.; PAVAN, A. C.; et al. Desempenho e Qualidade dos Ovos de Codornas de Quatro Grupos Genéticos. Revista Brasileira de Zootecnia, v.34, n.3, p.864-869, 2005.

MOURA, A. M. A.; OLIVEIRA, N. T. E.; THIEBAUT, J. T. L. et al. Efeito da temperatura de estocagem e do tipo de embalagem sobre a qualidade interna de ovos de codornas japonesas (coturnix japonica). Ciência e Agrotecnologia, v. 32, n. 2, p. 578-583, mar./abr., 2008. 

produção de ovos e qualidade dos ovos durante a conservação in natura

MOURA, A. M. A. de; FONSECA, J. B.; MELO, E. A.; et al. Características sensoriais de ovos de codornas japonesas (Coturnix japônica Temminck e Schlegel,1849) suplementadas com pigmentantes sintéticos e selenometionina. Ciência e Agrotecnologia, v.33, n.6, p.15941600, nov./dez., 2009.

NASCIMENTO, G. A. J. do; COSTA, F. G. P.; AMARANTE JÚNIOR, V. S. et al. Efeitos da substituição do milho pela raspa de mandioca na alimentação de frangos de corte, durante as fases de engorda e final. Ciência e Agrotecnologia, v.29, n.1, p.200-207, jan./fev. 2005.

NASCIMENTO, S. T. Determinação do balanço de calor em frangos de corte por meio das temperaturas corporais. 2010. 147 p. Dissertação (Mestrado em Ciências), Escola Superior de Agricultura "Luiz de Queiroz", Universidade de São Paulo, Piracicaba, 2010.

SARCINELLI, M. F.; VENTURINI, K. S.; SILVA, L. C. Características dos ovos. Boletim

Técnico. PIE-UFES: 00707. 2007.

ROSTAGNO, H.S. Tabelas brasileiras para aves e suínos: composição de alimentos e exigências nutricionais. 2 ed., Viçosa: UFV, 2005. 186p.

TEIXEIRA, A. S. Alimentos e Alimentação dos Animais. Volume II - Tabelas de composição dos alimentos e exigências nutricionais. 5 Ed. Lavras: UFLA-FAEPE, 2001. 141p.

TEIXEIRA, B. B.; TEIXEIRA, R. B; SILVA, L. P. da; et al. Estimação dos componentes de variância para as características de produção e de qualidade de ovos em matrizes de codorna de corte. Ciência Rural,v.42, n.4, p.713-717, abr. 2012.

UNIVERSIDADE FEDERAL DE VIÇOSA - UFV. Sistema de análises estatísticas e genéticas - SAEG. Viçosa: UFV. 150p. 1997. (Manual do usuário). 